\title{
Dualmode: Transportation's future
}

\author{
Francis D. Reynolds
}

Current transportation systems are in serious trouble in a number of ways. So, it is imperative that-besides trying to solve current traffic and safety problems with automatic highways, smart vehicles, or intelligent infrastructures-we begin taking a longer view, planning for the next 20 to 50 years.

In this installment of Intelligent Transportation Systems, Francis Reynolds proposes his view on a possible long-range solution to transportation problems such as jams, increasing volume, city and extraurban traffic, and energy and environmental issues. His proposal is fascinating and full of innovative ideas.

I'm sure that his article will intrigue many readers and that most will agree this is a necessary step toward a safer, cleaner, more efficient, and more comfortable way to transport people (and goods). But when will such a scenario become reality? How many of our readers would invest in such revolutionary ideas and would consider the time sufficiently mature to begin working on them?

If you're interested in following up on the ideas in this article, I suggest you contact Reynolds for a deeper discussion. For further information and for suggestions on this department, please contact me at broggi@ ce.unipr.it; www.ce.unipr.it/broggi.

-Alberto Broggi

n two or three decades, the predominant transportation system in much of the world will likely be dualmode transportation. We will use even more private cars but do it without our current problems by operating them in two distinct modes. We'll drive them in the normal manner on the streets, and

they'll travel automatically at high speeds on special guideways with no driver and their motors shut off. These guideways can be of several different types, but all will carry electricity to power the vehicles. Trips of more than several miles will use the guideways rather than the highways. We will travel more safely, more cheaply, more quickly, less stressfully, and with neither gasoline nor pollution.

Automated highway systems also use a manually driven and an automatic mode. However, dualmode systems incorporate most of the intelligence in the guideway network, not the car. Current AHS thinking concentrates on implementing automated lanes for specially equipped cars on existing highways. A dualmode system will cost more, because it will also require special guideways. In return, it will offer more than just the limited advantages of AHS; it will solve or greatly reduce most of our transportation problems and related environmental problems. And some of the things that dualmode transportation will do for society seemingly can't be done in any other acceptable way.

\section{What dualmode offers}

A dualmode system will reduce highway traffic to a dribble because most traffic will ride the high-capacity guideways instead. It will also reduce inner-city traffic congestion because a high percentage of cars going to the cities will not enter the downtown streets at all. Users will park these cars in, and retrieve them from, automatic parking facilities integral with the guideway system.

The guideways will carry most types of vehicles now used on streets and highways. The traffic's bulk will be private cars, but transit buses, transcontinental buses, rental cars, taxis, school buses, delivery trucks, cross-county freight traffic, and perhaps personal rapid-transit vehicles will also use the guideways. Most vehicles will run on both the streets and guideways, but crosscountry buses and long-distance freight vehicles will operate only on the guideways-with no drivers. Freight vehicles will be more like cargo containers than trucks.

The guideways will be at a different level from the streets, highways, and railroads to minimize the exposure of pedestrians, nonguideway vehicles, and trains to the automatic constant-speed vehicles on the guideways. The guideways will operate nonstop at full speed day and night, just as our highways would if they weren't jammed.

The guideway speed might be $60 \mathrm{mph}$ $(100 \mathrm{kph})$ in and around cities and a con- 
stant $200 \mathrm{mph}$ (320 kph) between cities. With synchronous propulsion (see the section "Linear synchronous motors"), the cars might travel one foot $(.3 \mathrm{~m})$ apart. Such numbers provide enormous system capacity. Using two-second minimum headways on the highways, as many American state police departments recommend, and assuming an average vehicle length of 15 feet $(4.6 \mathrm{~m})$, at $60 \mathrm{mph}$ a single guideway lane will carry the traffic of approximately 12 highway lanes. Between cities at $200 \mathrm{mph}$, one guideway lane will be the equivalent of 40 highway lanes. Adding more lanes will become a thing of the past.

The dualmode transportation system will also greatly reduce domestic airline traffic. When you include the time to make reservations, the trips to and from airports, parking, cancelled flights, late flights, baggage checking, security checks, and the rest, the 200-mph guideways will be faster than flying for trips up to perhaps 1,000 miles (1,600 kilometers). And guideway travelers will have privacy instead of someone else's crying baby. They will also have their own cars to use at their destinations instead of airport buses, rental cars, or taxis.

Oversized and heavy freight and cargo will doubtless continue to travel on the highways and railroads. Excessively large and heavy-duty guideways would cost too much, and most freight doesn't require what would be the energy-wasteful speeds of the intercity dualmode guideways. But moderate-size guideways will provide valuable shipping of time-critical freight such as mail, meat, produce, and consumer products. So, guideway freight should replace a lot of airfreight.

\section{Basic operation}

A driver wishing to enter the guideway system will drive into an "entry stop," shut off the motor, and key the number of the desired guideway exit into a keypad on the dashboard. That exit number will tell the navigation computer where to send the car and tell the billing computer how much to charge the customer for that trip.

Meanwhile, electronics in the entry stop will be reading a chip in the car that identifies it and provides other vital statistics. Simultaneously, an automatic system will check the operation of the car's parts that are essential to safe travel on the guideways. If a vehicle fails any of these requirements, it will be automatically denied access to the guideways and must return to the streets.

After these preliminaries, which might take 30 seconds, the system will accelerate the vehicle to guideway speed and merge it with the guideway traffic.

\section{Energy conservation}

Most dualmode cars will eventually be battery-electric or fuel-cell-electric for street use. There, they will only need to run at low speeds and for short distances. So, batteries or hydrogen tanks that are now inadequate for highway use will be more than adequate for just street use. In the early transition years, the cars will have internal-combustion engines because they will need to use highways where guideways are not yet available.

The additional electrical power that the guideways require will far exceed our present power grid's capacity. This additional power won't come from petroleum or natural gas; they will be largely depleted. However, we still have plenty of coal. Unfortunately, coal is far from "green." But even if we use coal instead of solar energy to push electrons through the guideway-power transmission lines, the overall dualmode system will be close to twice as efficient as automobiles. So, dualmode transportation will burn less fuel and therefore generate less global-warming $\mathrm{CO}_{2}$ than present transportation does.

\section{Maglev's promise}

In some proposed dualmode systems, cars ride on top of the guideways; other systems suspend the cars below overhead guideways. In some systems, the cars run directly on the guideways; other systems require interfacing "pallets" between conventional cars and the guideways. Some dualmode advocates propose supporting the vehicles on the guideways with pneumatic tires; others propose steel wheels on steel rails. But many advocates believe that maglev (magnetic levitation) guideways show the most promise.

Maglev trains are quite well developed, especially in Japan and Germany. They are fast, quiet, smooth, and safe. But passenger trains are largely obsolete whether they use wheels on rails or magnetic levitation. So, maglev trains will die in their infancy. But don't blame maglev per se for its misuse; it will have wonderful advantages for dualmode transportation. Some are obvious: if the cars are floating with motors off, they won't be wearing out. Nor will the guideways wear, so they won't develop dangerous faulty rails or potholes.

In the more common types of magnetic levitation, the magnetic field from ACpowered armature coils, in either the guideways or the cars, reacts with opposing field magnets in either a repulsion mode or an attraction mode (which requires a more complex configuration).

Linear electric motors. Maglev systems usually incorporate linear electric motors to propel vehicles. These linear motors are like ordinary AC motors except that they are laid out flat so that the working parts move linearly instead of rotating. In some cases the same magnets and coils can work for both levitation and propulsion. The motor's stator is built into the guideway, and its moving parts are attached to the levitated car. But the armature carrying the AC current can be in either the car or the guideway, with the field magnets in the opposite location.

If the guideways employ linear synchronous motors, all the cars will travel at precisely the same speed at all times, so the spacing between them will never change. Collisions will be virtually impossible. They will be like boxes on a conveyor belt or like plug-in electric clocks that keep exactly the same time because they all run synchronously on the same alternating current. One major advantage of LSM guideways is greatly increased system capacity due to remarkably lower minimum headways. Another is a greatly reduced failure rate due to a simpler system with much fewer parts. The simplification comes from eliminating the proximity sensors and velocity-control systems, which nonsynchronous guideways or an AHS requires.

True LSMs, like their rotary-synchronous-motor cousins, provide no starting torque when using normal AC power. Most synchronous-linear-motor dualmode advocates propose to accelerate the vehicles on ramps supplied with power of increasing frequency. Because the system can tailor that power's variable frequency, it can precisely merge an entering car with the mainline traffic in a minimum-length gap. Likewise, in the exit or deceleration ramps, power will gradually decrease in frequency, synchronizing the vehicles with it.

During descent of steep grades, the LSMs will act as synchronized alternator 
generators and provide dynamic braking. This will pump electrical energy back into the power grid rather than wasting it as brake heat.

During a power failure, the cars will still hold their spacing while decelerating. Autosynchronization of the LSMs will occur because they will still be electrically coupled through the guideways. Any car that tends to run more slowly than its mates will receive synchronous power generated by them so that it can keep up with them.

Inductive maglev. The HiLoMag dualmode system (http://faculty.washington. edu/jbs/itrans/hilo1.htm) would use conventional magnetic levitation and linear motors plus a less common type of maglev for guidance and switching. This type, sometimes called inductive maglev, requires no electrical input. Permanent magnets in the moving car induce a current and a corresponding magnetic field in fixed, electrically conductive rails in the guideways. This process generates a repulsion force. Figure 1 shows a levitated HiLoMag car on a guideway.

For the cars to switch from one guideway to another at full speed (the same as we merge with or exit highways at full speed), the switching would be initiated automatically in the vehicles, not by switching the track configuration, as occurs on railroads. The switching concept, which is basically that which the Morgantown People Mover and some other systems use, requires two normally parallel lateral guide rails on the guideways. At a junction, the guide rails separate; one follows one arm of the "Y," while the other follows the other arm.

Before a vehicle arrives at a junction, a switching command from the guideway computer system would direct a mechanism in the vehicle to cleave to either the left or right guide rail as the vehicle's route requires. The guide rails would be conductive and would provide zero-contact guidance and switching by means of laterally oriented inductive maglev. Because inductive maglev requires no electrical power, the system would guide cars safely even during a power failure.

Efficiency. Although the efficiency will vary widely with the details of the system, maglev combined with linear-motor propulsion will provide excellent efficiency

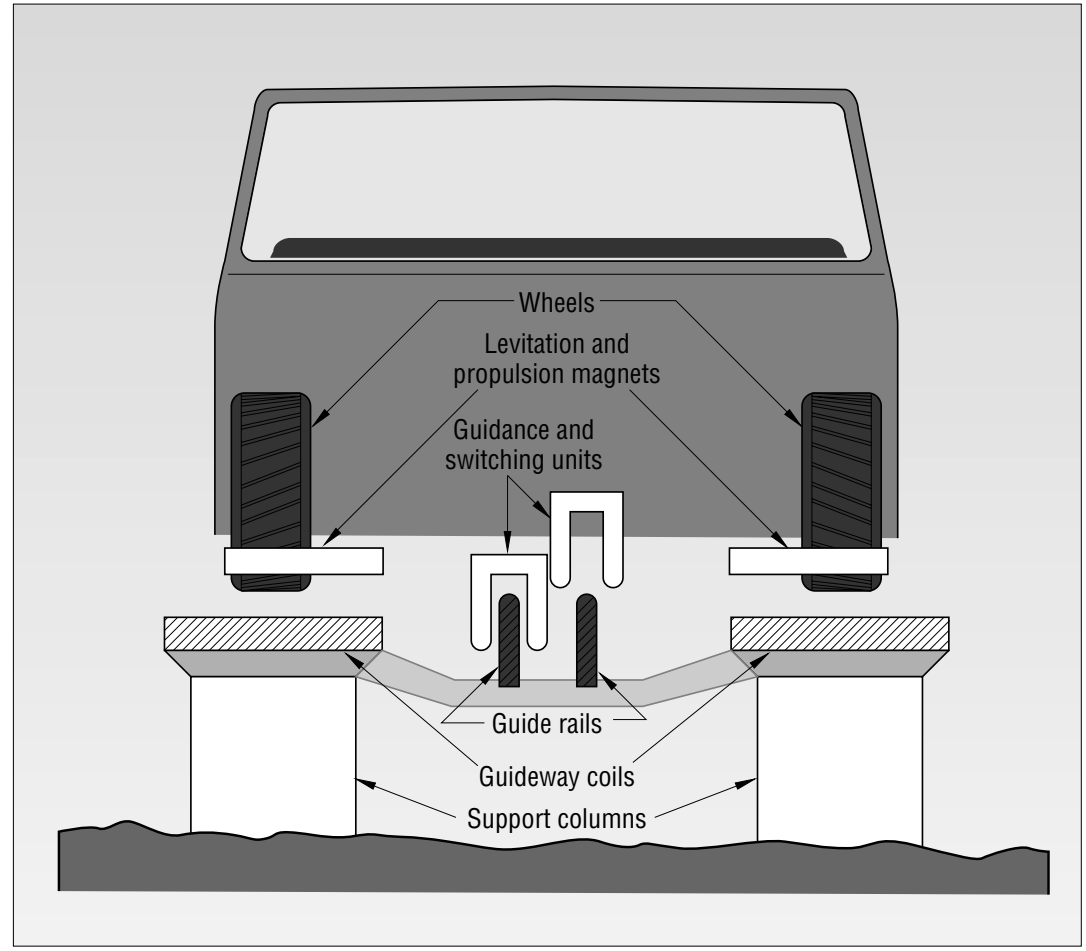

Figure 1. A levitated dualmode car on a guideway.

compared with pneumatic tires and internal-combustion engines. Contrary to what many people believe, magnetic support alone doesn't require energy any more than a structural column requires energy to support a roof. I have a novelty ballpoint pen that is supported in the air by permanent magnets. It has no battery, and the pen floats as high now as it did years ago. The magnets in the base are arranged to produce a swale in the composite flux field, providing a virtual nest in which the pen floats stably.

According to Matt Brogdon and his colleagues, "Maglev consumes per trip about one-seventh of the energy used by a Boeing 737-300." Another approach to estimating the relative efficiencies is to compare liftto-drag ratios. The $\mathrm{L} / \mathrm{D}$ of jet airliners is 18 to 20 . The L/D of the Bechtel maglev system is said to be 100 , while that of the Foster Miller maglev system is 170 .

Cost. Although Dualmode guideways will cost more initially than AHS lanes, they will use less energy. Dualmode vehicles might cost more or less than AHS vehicles, depending primarily on whether the dualmode system employs pallets. Cars that ride on pallets will cost less than true dualmode cars. But a palleted dualmode guideway system will cost more than a true-dualmode-car system, owing to the cost of the system-owned pallets, to additional computer complexity, and to additional ramp loops needed to automatically route empty pallets to where they are needed. These places will normally be in residential areas during morning rush hours and in business, shopping, and industrial areas during evening rush hours.

How much will a dualmode guideway system cost? Probably an average of 25 million to 50 million dollars per mile of guideway-hundreds of billions for the US national system. But the vehicles will not belong to the guideway companies, so they won't be part of the system cost any more than the cars on our highways are part of the highway system's cost. The guideway system will be paid for by automatically charging every vehicle that uses it (and essentially all vehicles will use it). A private-enterprise consortium, the government, or a combination of both could finance and operate the system. Because a dualmode system will be universally used as our highways are, it should never require subsidies.

\section{Now's the time to start}

We can't simply continue patching our present obsolete transportation systems. The patches are obviously not workingthe overall situation keeps getting worse rather than better. More and more, we see that none of the conventional projects and 


\section{Coming Next Issue}

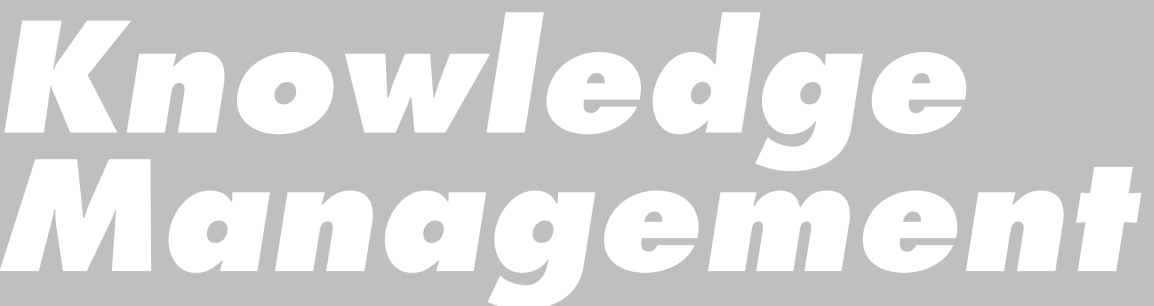

As knowledge management mafures, we are able to discuss richer applications and study the use of knowledge management systems. This issue will drill down on knowledge management use in business and provide specific industrial applications.

\section{For more information}

Jerry Schneider's extensive Innovative Transportation Technology Web site (http:// faculty.washington.edu/jbs/itrans) provides links to many dualmode transportation papers and Web pages. Two especially relevant pages are the "Dualmode Debate Page" (http://faculty.washington.edu/jbs/itrans/dual dbte.htm) and "Dualmode Transportation Concepts" (http://faculty.washington.edu/ jbs/itrans/dualmode.htm). Works of particular interest are

- the InTranSys dualmode system, http:// faculty.washington.edu/jbs/itrans/its. htm;

- Walter Velona's proposal, http://faculty. washington.edu/jbs/itrans/velona2.htm;

- John B. Hopkins' comments, http:// faculty.washington.edu/jbs/itrans/ hopkin2.htm;

- the Danish RUF (rapid, $u$ rban, flexible) system, http://faculty.washington.edu/ jbs/itrans/ruf1.htm;

- MegaRail Transportation Systems, www.megarail.com;

- MagneMotion (linear synchronous motor technology), www.magnemotion. com; and

- a Swedish dualmode system, www. swedetrack.com. proposals can do much good. Trains and automobiles are over 100 years old; they were 19th-century inventions. In their present forms they are obsolete. The only way to get high capacity and safe high speeds, keep the wonderful advantages of private cars, and solve transportation-related environmental problems is to design and build a universal system with modern technology for 21st-century traffic and lifestyles.

Many people have concluded that dualmode transportation addresses the greatest number of our transportation problems. It combines the best aspects of both privatecar transportation and public transportation, yet it reduces or eliminates most of their shortcomings. In particular, when our petroleum reserves are gone, a dualmode system would continue to operate because it does not depend on internal combustion engines.

A leader in a transportation technical society wrote to me, "Dualmode systems are something that we should keep in mind for the future, but it is too early to think about such revolutionary ideas." Does he realize that designing and implementing a dualmode system will take at least two decades? By that time most of our oil will be gone, and its price will be excessive. Global warming will be worse, air pollution will be worse, concrete will have replaced more flora, and the traffic jams will be intolerable.

\section{1} t last count, 22 different dualmode systems have been independently proposed. About one-fifth of these originated outside the US. A half-dozen or more inventors are now working together and with others on the Internet to refine the details of an optimum dualmode system. Unfortunately, in spite of this extensive research (see the "For more information" sidebar), the general public and most of the technical fraternity are not yet aware of the very promising and urgently needed dualmode technology.

\section{Reference}

1. M. Brogdon, J. Camp, D. James, and S. Wear, "Maglev: A Physics Viewpoint," http://bmes.ece.utexas.edu/ jcamp/physics/ final.html (current Nov. 2000).

Francis Reynolds is a private engineering consultant specializing in technological developments and the engineering evaluation and testing of prototypes. He is also an experienced corporate and private technical inventor who holds a number of patents. In addition, he is an invention evaluator for Washington State University's Innovation Assessment Center and was a director of the Inventor's Association of Washington. He received his BS in mechanical engineering from the University of Washington. He is an associate fellow of the American Institute of Aeronautics and Astronautics, a Registered Professional Engineer, and a member of the Flight Research Institute. He welcomes correspondence to freynoldsd@aol.com. 